\title{
STRATEGI PENGUATAN PROGRAM POSBINDU PENYAKIT TIDAK MENULAR DI KOTA BOGOR
}

\author{
Wahyu Pudji Nugraheni, ${ }^{1}$ Risky Kusuma Hartono ${ }^{2}$ \\ ${ }^{1}$ Pusat Humaniora dan Manajemen Kesehatan, Badan Penelitian dan Pengembangan Kesehatan \\ ${ }^{2}$ Sekolah Tinggi Ilmu Kesehatan Indonesia Maju (STIKIM)
}

\section{STRENGTHENING STRATEGIES OF POSBINDU PROGRAM FOR NONCOMMUNICABLE DISEASES IN BOGOR CITY}

\begin{abstract}
Background: The capacity of health human resources and the ability of the financial limitation become a threat for the sustainability of Posbindu program. The research aimed to analyze the strategy for strengthening Posbindu program for non-communicable diseases (NCD) control in Bogor.

Methods: This research used qualitative method based on case study approach. The main informants in this research from Dinkes, Puskesmas, cadres, and community.

Results: Posbindu PTM in Bogor had been visited by people from young to old age, but the number of cadres and equipment in each of Posbindu was different, the lack of training of cadres and the funding was still not optimal.

Conclusion: The strategy for strengthening the implementation of Posbindu program can be conducted by doing intensive NCD training for cadres from the medical staff, improved the health activities to increase the intensity of the presence of the community to the Posbindu program, and increasing the cross-sector cooperation.
\end{abstract}

Keywords: Posbindu, human resources capacity, cadre, financing, NCD

\begin{abstract}
ABSTRAK
Latar Belakang: Kapasitas SDM kesehatan dan kemampuan pendanaan yang terbatas menjadi ancaman keberlanjutan program Posbindu Penyakit Tidak Menular (PTM). Penelitian ini bertujuan untuk menganalisis strategi penguatan program Posbindu PTM di Kota Bogor.

Metode: Desain penelitian merupakan kualitatif dengan pendekatan studi kasus. Informan utama penelitian berasal dari Dinas Kesehatan, Puskesmas, kader, dan masyarakat.

Hasil Penelitian: Posbindu PTM kota Bogor telah dikunjungi oleh masyarakat dari kalangan usia muda hingga tua, namun jumlah kader dan peralatan setiap Posbindu berbeda, kader kurang mendapatkan pelatihan dan pendanaan yang belum maksimal.

Kesimpulan: Strategi berupa pelatihan yang lebih intensif terhadap kader mengenai PTM dari tenaga kesehatan, penambahan kegiatan kesehatan untuk meningkatkan intensitas kehadiran warga dan kerja sama lintas sektor menjadi alternatif yang dapat diterapkan untuk penguatan program Posbindu PTM.
\end{abstract}

Kata kunci: Posbindu, kapasitas sumber daya manusia, kader, pendanaan, penyakit tidak menular

\footnotetext{
${ }^{1}$ Alamat Koresponding: Wahyu Pudji Nugraheni, Pusat Humaniora dan Manajemen Kesehatan, Badan Penelitian dan Pengembangan Kesehatan, Kemenkes RI, Jl. Percetakan Negara No. 29 Jakarta 10560, Indonesia, Email: nugraheni_wp@yahoo.com
} 


\section{PENDAHULUAN}

Indonesia mengalami beban ganda masalah penyakit menular yang belum tuntas disertai perkembangan beban Penyakit Tidak Menular (PTM). Prevalensi PTM di Indonesia yaitu hipertensi usia $>18$ tahun $(25,8 \%)$, rematik $(24,7 \%)$, PPOK umur $\geq 30$ tahun $(3,8 \%)$, diabetes melitus $(2,1 \%)$, PJK umur $\geq$ 15 tahun $(1,5 \%)$, batu ginjal $(0,6 \%)$, hipertiroid umur $\geq 15$ tahun berdasarkan diagnosis $(0,4 \%)$, gagal jantung $(0,3 \%)$, gagal ginjal kronik $(0,2 \%)$, stroke $(12,1 \%)$, dan kanker $(1,4 \%) .{ }^{1}$ Sebagian besar jenis PTM menjadi beban jangka panjang bagi penderita dan cenderung tidak dapat disembuhkan kembali. $^{2}$

PTM terjadi akibat berbagai faktor risiko, seperti kebiasaan merokok, kebiasaan minum alkohol, jarang makan buah dan sayur, jarang melakukan aktivitas fisik, konsumsi gula dan garam berlebih. ${ }^{3,4}$ Faktor risiko tersebut akan menyebabkan terjadinya perubahan fisiologis di dalam tubuh manusia, sehingga menjadi faktor risiko antara lain tekanan darah meningkat, gula darah meningkat, kolesterol darah meningkat, dan obesitas. ${ }^{5,6}$ Hal utama yang perlu dilakukan dalam rangka penguatan program pengendalian PTM dilakukan dengan peningkatan kapasitas SDM dan kecukupan pendanaan program yang efektif. ${ }^{7}$

Pengendalian kematian akibat PTM dan pencegahan tembakau disepakati secara global setelah memasuki era kesepakatan Sustainable Development Goals (SDGs). ${ }^{8}$ Perhatian dunia terhadap PTM ini sebaiknya segera direspon dengan upaya program pengendaliannya di setiap negara termasuk di Indonesia. Salah satu strategi pengendalian PTM yang efisien dan efektif adalah pemberdayaan dan peningkatan peran serta masyarakat. ${ }^{9}$ Strategi ini sama halnya dengan upaya strategi pencegahan gangguan mental dengan mengutamakan pendekatan preventif dan promotif terhadap individu, keluarga dan masyarakat. ${ }^{10}$ Skema pencegahan utama PTM secara komprehensif perlu dilakukan dengan upaya bersama antara pemerintah, tenaga kesehatan dan masyarakat dengan menyediakan berbagai macam metode edukasi kesehatan dan deteksi dini dengan memanfaatkan penggunaan alat-alat canggih. ${ }^{11}$

Pemerintah Indonesia telah mencanangkan program Pos Binaan Terpadu (Posbindu) PTM sebagai wujud nyata bentuk pengendalian PTM melalui kegiatan pemberdayaan masyarakat. ${ }^{12}$ Kegiatan Posbindu PTM terbukti mampu meningkatkan pengetahuan, sikap mawas diri, dan status kesehatan masyarakat terhadap faktor risiko PTM sehingga peningkatan kasus PTM dapat dicegah. ${ }^{13}$ Selain itu, PTM yang berbiaya mahal dan bersifat katastropik dapat ditanggulangi sedini mungkin melalui serangkaian upaya pencegahan selain dengan peran implementasi program jaminan kesehatan nasional. ${ }^{14}$

Pelaksanaan Posbindu PTM berdasarkan pada Peraturan Menteri Kesehatan Nomor 71 Tahun 2015 tentang Penanggulangan Penyakit Tidak Menular Pasal 20 ayat 3 menyebutkan bahwa setidaknya terdapat kegiatan deteksi dini dan monitoring tindak lanjut dini faktor risiko PTM secara mandiri. ${ }^{12}$ Sedangkan Juknis kegiatan Posbindu PTM mensyaratkan 11 jenis kegiatan mampu dilaksanakan oleh Posbindu. ${ }^{15}$ Kota Bogor sebagai kota yang telah dilakukan studi kohort PTM menjadi wilayah yang tepat untuk diketahui program Posbindu PTM dan upaya penguatanya. Posbindu kota Bogor yang diharapkan menjadi contoh bagi kota atau kabupaten lain dalam implementasi pencegahan PTM apabila tidak mampu meningkatkan kemandirian hidup sehat masyarakat, sepi pengunjung, tidak didukung oleh SDM dan pendanaan yang cukup akan berujung pada kegagalan program pemerintah pada implementasi program Posbindu. Hal tersebut dapat terjadi karena kapasitas SDM dan kemampuan pendanaan yang terbatas pada program 
Posbindu. Oleh karena itu, penelitian ini bertujuan untuk menganalisis strategi penguatan Posbindu PTM dari aspek SDM, pendanaan dan keterlibatan masyarakat di Kota Bogor.

\section{METODE}

Penelitian ini merupakan jenis penelitian kualitatif secara pendekatan studi kasus dengan metode deskriptif analitik. Pendekatan studi kasus dipilih untuk mengetahui keadaan implementasi program Posbindu PTM yang rentan sepi pengunjung dan tidak mampu memandirikan masyarakat untuk hidup sehat. Penelitian ini diadakan di Kota Bogor dengan melibatkan instansi Dinas Kesehatan, Puskesmas, Posbindu, dan masyarakat di Kota Bogor. Sedangkan periode turun lapangan penelitian dilaksanakan pada Agustus sampai dengan Oktober 2017.

Teknik yang digunakan dalam penelitian yaitu wawancara mendalam dan observasi. Informan yang dipilih untuk wawancara ditetapkan secara langsung menggunakan prinsip kesesuaian dan kecukupan yaitu Kepala seksi PTM Dinas Kesehatan Kota Bogor, Kepala bagian Perencanaan Dinas Kesehatan Kota Bogor, Kepala Puskesmas, Kader Posbindu Ciwaringin dan Kebon Kelapa kota Bogor, masyarakat yang memanfaatkan Posbindu yang berusia 15 tahun ke atas dan Pembina Posbindu dari pihak kelurahan. Sedangkan observasi penelitian dilakukan dengan membuat catatan selama di lapangan dan foto kegiatan Posbindu PTM. Data sekunder penelitian didapatkan dari hasil kegiatan Posbindu PTM di Kota Bogor dan serangkaian peraturan perundangan yang dibahas sesuai dengan variabel penelitian.

Variabel penelitian yang digali secara tematik meliputi kapasitas SDM Kesehatan terutama kapasitas kader dalam pelaksanaan Posbindu PTM, pendanaan Posbindu PTM, partisipasi masyarakat mengunjungi Posbindu PTM dan potret observasi pelaksanaan Posbindu PTM. Sedangkan strategi penguatan
Posbindu PTM digambarkan dalam bentuk narasi berbagai masukan dari informan dan dukungan teori yang terkait.

Analisis data penelitian dilakukan dengan menggunakan bantuan aplikasi atlas.ti versi 7 yang merupakan salah satu aplikasi pengolah data kualitatif berbentuk kata-kata. ${ }^{16}$ Analisis yang dilakukan mencakup pembuatan matriks hasil wawancara mendalam dengan informan dan menangkap kutipan yang menguatkan hasil penelitian. Triangulasi yang diterapkan dengan menggunakan triangulasi metode, sumber, dan data. Selain itu, analisis data dilakukan dengan membuat word cloud untuk memetakan pihak-pihak yang cukup penting dalam keberlanjutan program Posbindu PTM.

Berbagai temuan dari hasil wawancara mendalam, observasi, dan data sekunder dilakukan pengolahan sesuai dengan variabel utama penelitian. Hasil penelitian menyajikan petikan hasil wawancara mendalam dengan informan penelitian, tabel, dan narasi solusi strategi untuk penguatan program Posbindu PTM di Bogor. Selain itu, hasil penelitian juga dipertajam dengan diskusi sesuai dengan hasil penelitian sejenis terdahulu.

\section{HASIL PENELITIAN}

\section{Penguatan Kapasitas SDM Posbindu PTM}

Menurut informasi kader Posbindu PTM di Kota Bogor, tugas kader dalam pelaksanaan program pengendalian PTM yang dilakukan di Posbindu sudah sesuai dengan Petunjuk Teknis (Juknis) Posbindu PTM. Sesuai penjelasan informan, tugas kader yaitu mengingatkan jadwal dan mengajak masyarakat memeriksakan diri ke Posbindu, menyiapkan perlengkapan Posbindu termasuk form pendaftaran, peralatan, media penyuluhan dan perlengkapan pendukung seperti meja dan alat-alat tulis. Tugas kader PTM di Kota Bogor telah berjalan sesuai dengan tugas pokok yang terdapat dalam kebijakan juknis.

Sesuai hasil observasi penelitian, tugas kader ketika ada masyarakat yang hadir ke 
Posbindu yaitu membantu proses menimbang berat badan, mengukur tensi, mengukur lingkar perut dan melakukan pencatatan. Selain itu kader mempersiapkan makanan tambahan kepada masyarakat apabila diperlukan. Bahkan kader juga menyempatkan diri untuk mengunjungi rumah masyarakat sekitar yang tidak sempat hadir datang periksa ke Posbindu PTM.

Kader Posbindu PTM masih menghadapi kendala internal seperti tugas kader yang masih merangkap dalam 1 Posbindu, laporan kader kepada Puskesmas sering mengalami keterlambatan, dan ternyata ada sebagian wilayah yang kegiatan Posbindu nya tidak berjalan dengan rutin. Hambatan tersebut berpotensi sebagai tanda-tanda penurunan kepuasan dan motivasi kerja kader. Berikut pernyataan informan kader.

Kader masih merangkap, kendalanya secara administratif, laporan sering terlambat, dan ada beberapa wilayah yang pelaksanaan Posbindu tidak rutin (Kader)

Informan kader dan pembina kader merasa bahwa pelatihan yang pernah dilakukan sangat jarang. Berbeda dengan petugas kesehatan dari fasilitas kesehatan yang lebih sering mendapatkan frekuensi pelatihan terkait PTM yang difasilitasi oleh dinas kesehatan. Berikut penjelasan informan terkait kendala tersebut.
Ada pelatihan tetapi sudah lebih dari 5 tahun yang lalu, saat belum ada Posbindu PTM (Kader)

Pernah mendapatkan pelatihan tentang PTM yaitu cara melakukan penimbangan dan lingkar perut, serta menghitung IMT, Pelatihan senam lansia yang pemateri berasal dari Dinkes dan dokter (Pembina Kader)

Jarang diadakan pelatihan untuk pembina kader. Sehingga tugas pokok fungsi Pembina kader ya menjadi kurang tahu (Kader)

Terdapat pelatihan dan workshop yang diselenggarakan oleh Propinsi atau Kemenkes. Dengan frekuensi kurang lebih 1 kali per 3 bulan. Staf Dinkes seksi PTM akan dikirim untuk pelatihan yang bersifat umum atau tingkat kota. Dokter, perawat atau bidan sebagai pemegang program PTM di puskesmas akan dikirim untuk pelatihan spesifik layanan (Seksi PTM Dinas Kesehatan)

\section{Pendanaan Posbindu PTM}

Berdasarkan penjelasan informan penelitian, pembiayaan program Posbindu PTM di Kota Bogor didapatkan dari berbagai macam sumber. Dana berasal dari pendanaan kegiatan yang bersifat preventif dan promotif yang dialokasikan untuk berbagai program pengendalian PTM termasuk Posbindu PTM dari pemerintah pusat dan pemerintah daerah. Tabel 1 menjelaskan asal pembiayaan program pengendalian PTM.

Tabel 1.

Asal Pembiayaan Program Pengendalian PTM, 2017

\begin{tabular}{lll}
\hline \multicolumn{2}{c}{ Asal Biaya Program PTM } & \multicolumn{1}{c}{ Keterangan } \\
\hline $\begin{array}{l}\text { Anggaran Pendapatan Belanja Nasional } \\
\text { (APBN) }\end{array}$ & $\begin{array}{l}\text { Termasuk anggaran kesehatan yang disalurkan ke kementerian } \\
\text { kesehatan, kementerian lain terkait kesehatan, dana desa, maupun } \\
\text { bantuan operasional kesehatan (BOK) }\end{array}$ \\
Anggaran Pendapatan Belanja Daerah (APBD) & $\begin{array}{l}\text { Dana dari APBD untuk kegiatan PTM yang bersifat rutin dan tidak } \\
\text { rutin }\end{array}$ \\
Bantuan Operasional Kesehatan (BOK) & $\begin{array}{l}\text { Dana kesehatan yang khusus digunakan untuk kegiatan upaya } \\
\text { preventif dan promotif }\end{array}$ \\
\hline
\end{tabular}

Sementara itu, hasil penelitian menemukan bahwa total pembiayaan sekali kegiatan di salah satu Posbindu PTM di Kota Bogor didapatkan nilai sebesar Rp469.000,00.
Pengeluaran tersebut setara dengan Rp9.380,00 per orang. Pengeluaran tersebut masih tergolong minim jika dibandingkan dengan berbagai sumber pembiayaan program 
pengendalian PTM yang mampu menghasilkan dana lebih besar.

Respon masyarakat kota Bogor terhadap program PTM khususnya kegiatan Posbindu secara umum memberikan respon yang positif dan disambut baik oleh warga. Sebagian kecil masih terdapat tantangan diantaranya kejenuhan warga terhadap program Posbindu PTM dan tuntutan program agar lebih dibuat komprehensif. Berikut respon masyarakat terhadap program PTM:

Kurangnya kesadaran warga

Warga berharap pengobatan di Posbindu dan meminta obat.

Warga takut stres karena mengetahui penyakit. Masyarakat jenuh dan sekitar $20 \%$ masyarakat tidak hadir.

Remaja sedikit yang mengikuti Posbindu karena sekolah atau menganggap usia masih muda. (Masyarakat)

\section{Partisipasi Masyarakat Berkunjung ke Posbindu PTM}

Indonesia sebagai negara berkembang perlu banyak belajar mengenai upaya menghindari penolakan masyarakat terhadap kegiatan program PTM. Sesuai dengan penjelasan informan kader, upaya peningkatan partisipasi masyarakat untuk hadir ke Posbindu Kota Bogor dilakukan dengan sosialisasi segala bentuk program PTM kepada masyarakat. Menurut umpan balik dari informan cara-cara yang dapat dilakukan dalam sosialisasi antara lain penyebaran informasi via website, media sosial, spanduk atau leaflat atau kontak langsung ke masyarakat via nomor telepon dan email pribadi. Upaya lain yang dapat dilakukan yaitu dengan membuat kegiatan-kegiatan yang mampu menarik perhatian masyarakat dari berbagai kelompok usia. Kegiatan tersebut misalnya pengobatan gratis, kegiatan sepeda santai, pemberian hadiah doorprize kepada peserta aktif, dan lain sebagainya.

\section{Peserta Usia Muda dan Tua di Posbindu} Kebon Kelapa Kota Bogor, 2017
Salah satu Posbindu yang dapat dijadikan best practice di Kota Bogor yaitu Posbindu Kebon Kelapa. Sesuai dengan hasil observasi yang dilakukan pada Posbindu tersebut pada 21 Oktober 2017, peserta yang hadir dari berbagai kelompok usia muda hingga tua. Namun, hasil observasi penelitian secara keseluruhan lokasi Posbidu ditemukan bahwa masih belum terdapat kesamaan jumlah kader, kelengkapan alat, metode Posbindu dan belum ada kesamaan pihakpihak yang melakukan monitoring dan evaluasi Posbindu PTM dalam satu lingkup kota Bogor. Oleh karena itu, perlu adanya standar minimal mengenai kelengkapan alat dan metode dalam sebuah Posbindu PTM.

\section{Strategi Penguatan Posbindu PTM}

Keseluruhan hasil analisis penelitian kemudian dibuat pemetaan dalam bentuk word cloud. Kata-kata seperti kader, masyarakat, pelatihan, sosialisasi, rutin dan anggaran menjadi kata yang sering diucapkan oleh seluruh informan penelitian ini. Kader menjadi kata-kata yang paling sering diucapkan. Kader Posbindu PTM yang didukung oleh petugas Puskesmas dan Dinas Kesehatan memang perlu mengembangkan program yang bersifat preventif dan preventif seperti deteksi atau pemeriksaan penyakit untuk mampu menarik minat masyarakat agar tetap konsisten hadir dalam program Posbindu PTM.

Titik analisis lain pada pelaksanaan Posbindu PTM yang masih perlu mendapatkan perhatian yaitu 1) masih kurang lengkapnya prasarana yang mendukung kelengkapan Posbindu seperti tidak ada alat cek gula darah, alat cek kolesterol, dan alat cek IVA. 2) masih belum maksimalnya monitoring dan evaluasi yang semestinya dilakukan oleh instansi Dinas Kesehatan Kota Bogor dan aparat desa setempat (baik itu RW, kelurahan, atau kecamatan). 3) masih kurangnya upaya kerja sama lintas sektor 
yang lebih luas agar program Posbindu dapat berjalan lebih komprehensif.

\section{PEMBAHASAN}

Permenkes Nomor 65 Tahun 2013 Tentang Pedoman Pelaksanaan dan Pembinaan Pemberdayaan Masyarakat Bidang Kesehatan Bab III menyebutkan bahwa peningkatan keberdayaan masyarakat berarti peningkatan kemampuan dan kemandirian masyarakat agar dapat mengembangkan diri untuk mencapai derajat kesehatan yang lebih baik. ${ }^{17}$ Kader sebagai sukarelawan dan perantara upaya peningkatan kesehatan masyarakat tersebut perlu mendapat dukungan dari Kementerian Kesehatan. ${ }^{18}$ Begitu juga dengan dukungan peran kader dalam keberlangsungan program Posbindu PTM yang perlu mendapatkan perhatian dari Kementerian Kesehatan. Berdasarkan hasil penelitian ini menunjukkan bahwa tugas kader Posbindu PTM di Kota Bogor dalam pelaksanaan program pengendalian PTM yang dilakukan di Posbindu sudah sesuai dengan Juknis Posbindu PTM. ${ }^{15}$

Menurut Eilish et al pemberian bayaran bukan satu-satunya elemen dalam kepuasan kerja kader, melainkan pemberian motivasi dari manajer kesehatan lebih memiliki peran penting. ${ }^{19}$ Hasil penelitian ini menunjukkan bahwa motivasi kader untuk menghidupkan kegiatan Posbindu sudah bagus terlihat dari adanya kunjungan kader ke rumah warga yang tidak hadir ke Posbindu. Tenaga kesehatan Puskesmas sebaiknya terus meningkatkan motivasi para kader terutama kepada mereka yang mengalami keterlambatan pelaporan ke Puskesmas. Apalagi sesuai dengan hasil penelitian ini, pelatihan kepada kader Posbindu juga jarang diberikan. Pelajaran penting kunci keberhasilan pelaksanaan program kesehatan yang dibantu oleh peran kader menurut Sudhi et al yaitu membangun jaringan dan dukungan dari rekan-rekan kader, memastikan pemberian pelatihan yang memadai, mengembangkan hubungan dengan para tenaga kesehatan profesional, dan mempersiapkan tunjangan kerja yang memadai. ${ }^{20}$

Selain penguatan kapasitas SDM, pendanaan merupakan salah satu aspek penting untuk mempertahankan keberlangsungan suatu program kesehatan. Sedangkan pendanaan Program Posbindu PTM di Kota Bogor pada penelitian ini masih tergolong minim jika dibandingkan dengan berbagai sumber pembiayaan program pengendalian PTM yang mampu menghasilkan dana lebih besar. Berdasarkan hasil penelitian di Amerika, upaya penurunan konsumsi garam berlebih saja memerlukan pendanaan mencapai 1 Milyar pada lebih dari 1 dekade lalu. ${ }^{21}$ Apalagi untuk pencegahan PTM melalui program preventif dan promotif pada Posbindu PTM. Hasil penelitian Mays juga mengungkapkan bahwa pendanaan program kesehatan masyarakat yang cukup mampu menurunkan kematian akibat PTM sebesar $6,9 \%$ pertahun. $^{22}$

Pendanaan program yang minim kurang mendukung semangat kebijakan Permenkes Nomor 39 Tahun 2016 Tentang Pedoman Penyelenggaraan Program Indonesia Sehat dengan Pendekatan Keluarga yang menyebutkan bahwa dalam hal pengembangan sumber daya prioritas dana kesehatan diperuntukan bagi kelengkapan sarana Puskesmas, penyelenggaraan pelatihan tenaga kesehatan, dan biaya operasional. ${ }^{23}$ Kekhawatiran yang diungkapkan oleh Frieden yaitu semakin banyak program kesehatan masyarakat yang tidak mencapai hasil yang diinginkan karena pendanaan yang terbatas dan tidak stabil, kurangnya sarana untuk meningkatkan kinerja dan komitmen politik yang tidak memadai. ${ }^{24}$ Oleh karena itu, dukungan dana untuk operasional program menjadi salah satu aspek yang diperlukan dalam pelaksanaan Posbindu PTM.

Secara sistematic review Asha et al mengungkapkan bahwa partisipasi masyarakat pada program-program kesehatan yang bersifat preventif mencapai $78 \%$ pada negaranegara maju. ${ }^{25}$ Pada negara berkembang, 
pembelajaran yang didapatkan dari penelitian di negara Iran ditemukan bahwa sikap rentan penolakan dari masyarakat untuk dilakukan edukasi kesehatan masih menjadi tantangan. ${ }^{26}$ Sedangkan respon masyarakat kota Bogor terhadap kegiatan Posbindu pada hasil penelitian ini memberikan respon yang positif dan disambut baik oleh warga. Dengan kata lain tidak ada kekhawatiran penolakan dari masyarakat. Masyarakat juga telah mendukung upaya pencegahan PTM melalui program Posbindu.

Hasil analisis secara world cloud menunjukkan bahwa masih kurangnya upaya kerja sama lintas sektor yang lebih luas agar program Posbindu dapat berjalan lebih komprehensif. Upaya yang dapat dikembangkan yaitu dengan melaksanakan public-private partnership untuk melakukan back up ditengah kemampuan sektor publik yang kurang adekuat, kurang efektif, dan kurang sumber daya manajemen. ${ }^{27}$ Upaya menjaga eksistensi program PTM di Kota Bogor perlu dilakukan dengan menjaga dan mengembangkan perhatian dari stakeholder lintas sektor baik itu dari lembaga pemerintah Bapeda, dinas sosial, dinas lingkungan hidup, dan lain sebagainya. Selain itu, tidak menutup kemungkinan Lembaga pemerintah berkolaborasi dengan lembaga swasta seperti

\section{DAFTAR PUSTAKA}

1. Riskesdas. Riset Kesehatan Dasar 2013. Jakarta: Kementrian Kesehatan: Kementerian Kesehatan RI; 2013.

2. Kroll M. Challenges to the Surveillance of Non-Communicable Diseases - a Review of Selected Approaches. J BMC Public Heal. 2015; vol 15(1):1243.

3. Echouffo-Tcheugui JB, Kengne AP. Chronic non-communicable diseases in Cameroon - burden, determinants and current policies. Global Health. 2011;7(1):44.

4. Thakur JS, Jeet G, Pal A, Singh S, Singh A, Deepti SS, et al. Profile of risk factors for non-communicable diseases in Punjab, Northern India: Results of a state-wide STEPS survey. PLoS One.
LSM, lembga penelitian, dan lembaga pendidikan. Dengan eksistensi dan inovasi program PTM melalui Posbindu PTM akan terus berlanjut.

\section{KESIMPULAN DAN SARAN}

Penelitian ini menyimpulkan bahwa Posbindu PTM kota Bogor telah dikunjungi oleh masyarakat dari usia muda hingga tua, Selain itu, respon masyarakat belum menyambut baik dengan sebagian besar masih tidak hadir dalam kegiatan Posbindu PTM. Kapasitas SDM terutama kader dan pendanaan program Posbindu PTM belum ditingkatkan secara optimal. Petugas kesehatan sebaiknya lebih intensif memberikan pelatihan kepada kader dan bersama dengan kader mengajak masyarakat untuk mau hadir dan berpartisipasi dalam program Posbindu PTM. Alternatif strategi yang dapat dilakukan yaitu penambahan kegiatan seperti pengobatan gratis, kegiatan sepeda santai, dan doorprize bagi peserta untuk menarik minat warga agar mau berpartisipasi hadir dalam Posbindu PTM. Pemerintah daerah sebaiknya mengupayakan kerjasama lintas sektor agar kegiatan Posbindu PTM semakin komprehensif.

2016;11(7):1-16.

5. Stringhini S, Forrester TE, Plange-Rhule J, Lambert E V., Viswanathan B, Riesen $\mathrm{W}$, et al. The social patterning of risk factors for noncommunicable diseases in five countries: Evidence from the modeling the epidemiologic transition study (METS). BMC Public Health. 2016;16(1):1-10.

6. Jr VD, Malcolm S, Crompton L, Vaddiparti K, Mramba LK, Striley C, et al. Community-based diagnosis of noncommunicable diseases and their risk factors in rural and urban Haiti : a crosssectional prevalence study. BMJ Open. 2018;1-8.

7. Nuthulaganti $T$, Umubyeyi $B, S c$ MN, Nyemazi JP, Uwayezu A, Sc MN, et al. Special Report The Human Resources for 
Health Program in Rwanda - A New Partnership. N Engl J Med. 2013; November.

8. Mondal S, Belle S Van. India's NCD strategy in the SDG era: are there early signs of a paradigm shift? Global Health. 2018;1-9.

9. Sethi S, Jonsson R, Skaff R, Tyler F. Community-Based Noncommunicable Disease Care for Syrian Refugees in Lebanon. Glob Heal Sci Pract. 2017;5(3):495-506.

10. Ayuningtyas D, Misnaniarti, Rayhani M. Analisis Situasi Kesehatan Mental pada Masyarakat di Indonesia dan Strategi Penanggulangannya. J Ilmu Kesehat Masy. 2018;9(1):1-10.

11. Hartono RK. Global Stakeholders Schemes for Preventing Burden NonCommunicable Diseases, Lesson Learnt for Indonesia. Proc Int Conf Soc Sci. 2018;1(1).

12. Kementerian Kesehatan. Peraturan Menteri Kesehatan Nomor 71 Tahun 2015 tentang Penanggulangan Penyakit Tidak Menular. Jakarta: Kementerian Kesehatan RI; 2015.

13. Purdiyani F. Pemanfaatan Pos Pembinaan Terpadu Penyakit Tidak Menular (Posbindu Ptm) Oleh Wanita Lansia Dalam Rangka Mencegah Penyakit Tidak Menular Di Wilayah Kerja Puskesmas Cilongok 1. J Kesehat Masy. 2016;4(1):470-80.

14. Nugraheni WP, Hartono RK. Catastrophic Health Spending Determinants of Indonesian Household in the First Year Implementation of JKN Program. Bul Penelit Kesehat. 2017;45(1):27-36.

15. Kementerian Kesehatan. Petunjuk Teknis POS Pembinaan Terpadu Penyakit Tidak Menular (Posbindu PTM). Jakarta: Kementerian Kesehatan RI; 2012.

16. Hwang S. Utilizing qualitative data analysis software: A review of Atlas. ti. Soc Sci Comput Rev. 2008;26(4):51927.

17. Kementerian Kesehatan. Peraturan Menteri Kesehatan Nomor 65 Tahun 2013 Tentang Pedoman Pelaksanaan dan Pembinaan Pemberdayaan Masyarakat Bidang Kesehatan. Jakarta: Kementerian Kesehatan RI; 2013.
18. Besada D, Goga A, Daviaud E, Rohde S, Chinkonde JR, Villeneuve S, et al. Roles played by community cadres to support retention in PMTCT Option B+ in four African countries: a qualitative rapid appraisal. BMJ Open. 2018;8(3):1-12.

19. McAuliffe E, Manafa O, Maseko F, Bowie C, White E. Understanding job satisfaction amongst mid-level cadres in Malawi: the contribution of organisational justice. Reprod Health Matters. 2009; 17(33):80-90.

20. Sodhi S, Banda H, Kathyola D, Joshua M, Richardson F, Mah E, et al. Supporting middle-cadre health care workers in Malawi: lessons learned during implementation of the PALM PLUS package. (Special Issue: Uptake and impact of research for evidencebased practice: lessons from the Africa Health Systems Initiative's research. BMC Health Serv Res. 2014;14(Suppl 1):1-8.

21. Beaglehole R, Ebrahim S, Reddy $S$, Voute J, Leeder S. Prevention of chronic diseases: a call to action. Lancet. 2007;370(9605):2152-7.

22. Mays GP, Smith SA. Evidence links increases in public health spending to declines in preventable deaths. Health Aff. 2011;30(8):1585-93.

23. Kementerian Kesehatan. Peraturan Menteri Kesehatan Nomor 39 Tahun 2016 Tentang Pedoman Penyelenggaraan Program Indonesia Sehat dengan Pendekatan Keluarga. Jakarta: Kementerian Kesehatan RI; 2016.

24. Frieden TR. Six Components Necessary for Effective Public Health Program Implementation. Am J Public Health. 2014 Jan 26;104(1):17-22.

25. George AS, Mehra V, Scott K, Sriram V. Community participation in health systems research: A systematic review assessing the state of research, the nature of interventions involved and the features of engagement with communities. PLoS One. 2015;10(10):1-25.

26. Rabiei K, Kelishadi R, Sarrafzadegan N, Abedi HA, Alavi M, Heidari K, et al. Process evaluation of a community-based program for prevention and control of non-communicable disease in a developing country: The Isfahan Healthy 
Heart Program, Iran. BioMed Cent. 2000;14:1-14.

27. Nishtar S. Public-private "partnerships" in health - A global call to action. Heal Res Policy Syst. 2004;2:1-7. 